\title{
correspondence
}

\section{Tank mentality}

SIR-It is disappointing to find the editor of Nature advocating the use of think tanks (Nature, 247, 169; 1974). A tank is conceptually a rather isolated system. It has inflow and outflow pipes and, hopefully, check valves but it does not otherwise interact with the outside world. Interaction, however, as Robert Eisler used to emphasise, is the basis of our sense of reality. It requires a tank mentality to lift the customer-contractor principle from one field, trade and manufacture, where it is appropriate, to another, research and development, where it is not. A customer may reasonably contract to purchase a specifiable product such as a type of refrigerator, the performance and production costs of which are known. In contrast, it is a grave risk (outside the tank world) to make a contract for some system which has not previously existed, in the development of which materials and systems are to be used in a new way. What but a tank mentality could give rise to phenomena like the notorious groundnuts scheme, could accept 'estimates' for the costs of certain Rolls-Royce engines or for Concorde or could envisage estimating the cost of producing a new crop variety in agriculture with specified yield and characteristics of resistance to disease.

The conflict between planning or drawing office, which produces a design, and the shop floor, which finds it impractical, is too common. As the scale of human planning increases, the drawing office becomes larger and more distant from operational reality. Planner and producer become more widely separated; more impractical, damaging or disastrous schemes are floated. What is needed is a thinker-doer mentality. Planners should leave their offices to participate in the execution of their plans to return as wiser men taught and stimulated by their shop floor or field experience.

It will be protested that some can think but cannot do and are better in the planning office, whereas others can do but cannot think and are better on the shop floor. True, but neither of these groups should be given responsibility beyond its limited experience for evaluating or developing new schemes. Positive steps are needed to provide a supply of citizens experienced and capable in both activities, thinking and doing.

Science has shown great success at prediction from general principles but if hubris or just crass ignorance should lead us to underestimate the complexity of the world about us, we shall fall. Let us not forget the advice of Columella, author of that fascinating encyclopaedia of agricultural experience, the $D e R e$ Rustica, written in the first century of our era (I quote from the Loeb Classical Library edition, 1960, Book I, 1, 16) :

"Usus et experientia dominantur in artibus, neque est ulla disciplina, in qua non peccando discatur."

"It is practice and experience that hold supremacy in the crafts, and there is no branch of learning in which one is not taught by one's own mistakes."

\section{Yours faithfully,}

33 Manor Rd,

H. $\mathrm{H}_{\mathrm{ACK}}$

Henely-on-Thames,

Oxfordshire

\section{ERTS}

SIR,-Due to postal delays I have only recently been able to read your editorial "ERTS-Technological Success, Scientific Failure?" (Nature, 245, 345; 1973). To me it was a thoughtful questioning of a programme involving a combination of science, technology, and bureaucracy.

I have had a bit of experience with geologic interpretation of space imagery, which has a distinct advantage when one wants to step back for a regional perspective of major structural trends that cannot at present be viewed in other ways. Mosaics of aerial photographs are almost always uneven in quality, the unevenness greatly inhibiting a regional analysis. Enough has been said about the necessity of ground-truth (confirming one's interpretation of imagery data by checking features on the ground) for one to appreciate the work and expense involved in analysing ERTS imagery. It is worth emphasising (as you did) that the resolution is only sufficient for viewing large features, although, as regional geologic trends can often be viewed as large features ERTS is still quite useful here. In other words, aerial and space imagery are not mutually competitive, but are complementary.

You also rightly note that weather and constant sun angle conditions mask many areas as well as many features within a given area. But weather conditions are as much a problem for conventional aerial surveys in areas such as tropical, developing Ghana. Here a
Canadian team has been stationed for a couple of years trying to conduct a survey that is usually hampered by cloud cover during the rainy season, and thick dust cover for much of the dry season. Nevertheless, the crew must stay here to be prepared to fly on that rare day when conditions are right. Similar climatic hindrances exist over much of the earth's surface; and I am sure that quite a lot of money is similarly spent on conventional aerial surveys elsewhere with only meagre results during long periods, unless one is satisfied with only radar imagery (which is better than nothing, but has considerable limitations). ERTS may not be especially expensive in this regard at least in operating costs, when scale of coverage is considered.

As an earth scientist I feel that ERTS must be tested for some time, eventually proving itself a scientific, technological, and economic success or failure. What worries me is that the agencies involved, such as NASA and the United States Geological Survey's Earth Resources Observation Systems (EROS) programme might, for short term prestige purposes prematurely push to prove ERTS by spending on expansion before such expansion is justified. There certainly are indications of overeagerness to declare ERTS a success, and to rapidly expand the programme. For example, about three years ago, when EROS was pushing for--and receiving-large budget increases, I saw a promotional brochure proclaiming that "automated snow mapping" had been accomplished. Having done field work in their study area I had a good chilly laugh noting that their claimed delineation between "thick" and "thin" snow cover was actually a map of the tree line! In their haste to "prove" a point, they must have failed to make that essential groundtruth check.

Though I disagree with you in some details, my general opinion is similar. NASA shouldn't consider ERTS-B until scientists and technologists outside the sponsoring agencies have concluded that a successor to ERTS-A would be worthwhile, and that at least part of the additional sea of data would be analysed. But ERTS-B should not be forgotten, only relegated to the subconscious.

Yours faithfully,

David A. Hastings

Department of Physics

University of Science and Technology Kumasi, Ghana 